\title{
JULGAMENTO CLÍNICO EM ENFERMAGEM: A CONTEXTUALIZAÇÃO DO DESENVOLVIMENTO DE COMPETÊNCIAS E HABILIDADES
}

\author{
Maria Helena Aparecida Costa ${ }^{1}$ \\ Talita Aparecida Rodrigues Devechi ${ }^{2}$ \\ Vanessa Aparecida Fernandes ${ }^{3}$ \\ Maria Aparecida Xavier Moreira da Silva ${ }^{4}$ \\ Márcio Antonio de Assis ${ }^{5}$
}

Resumo: O julgamento clínico é uma das competências do enfermeiro e está ligado ao ato de julgar as necessidades de cuidados de cada indivíduo e ao ato de elaborar o planejamento da assistência de enfermagem a ser realizada ao paciente, de forma que possa atender às suas necessidades e expectativas. Desenvolver a habilidade desse julgamento tem sido um grande desafio tanto para as instituições de ensino superior quanto às instituições de saúde. Este é um estudo de natureza descritiva, exploratória e com abordagem quanti-qualitativa que foi realizado com enfermeiros, tendo como principal objetivo contextualizar o processo do desenvolvimento do julgamento clínico em enfermagem. A pesquisa mostrou que o desenvolvimento de competências e habilidades para o julgamento clínico inicia-se, com muita deficiência, na formação acadêmica, pois nem sempre a teoria está associada à prática vivenciada em campos de estágio, sendo fortalecido somente na prática profissional do dia a dia. Portanto, há necessidade de mudanças emergentes para o cenário do ensino em enfermagem de forma que envolva ainda mais as instituições responsáveis pela formação do enfermeiro e que se desenvolva mais estudos que possam subsidiar o processo de desenvolvimento do julgamento clínico.

Palavras-chave: Processo de Enfermagem; Julgamento Clínico; Cuidados de Enfermagem; Segurança do Paciente; Tomada de Decisão.

\footnotetext{
${ }^{1}$ Enfermagem/Universidade de Mogi das Cruzes, Brasil. E-mail: mariahcosilva@gamil.com.

2 Enfermagem/Universidade de Mogi das Cruzes, Brasil. E-mail: devechi_talita@hotmail.com.

3 Enfermagem/Universidade de Mogi das Cruzes, Brasil. E-mail: vanessafernandes.a@gmail.com.

${ }^{4}$ Enfermagem/Universidade de Mogi das Cruzes, Brasil. E-mail: maria.silva@umc.br.

${ }^{5}$ Enfermagem/Universidade de Mogi das Cruzes, Brasil. E-mail: marcioassis80@gmail.com.
} 